\title{
English Language Writing Anxiety among Final Year Engineering Undergraduates in University Putra Malaysia
}

\author{
Lau Sing Min \\ Universiti Putra Malaysia \\ E-mail: singmin911@hotmail.com \\ Nurhazlini Rahmat \\ Universiti Putra Malaysia
}

Doi:10.7575/aiac.alls.v.5n.4p.102

URL: http://dx.doi.org/10.7575/aiac.alls.v.5n.4p.102
Received: 22/05/2014

Accepted: 03/07/2014

\begin{abstract}
Second Language Writing Anxiety (SLWA) is considered one of the most crucial factors affecting all second language learning. This study focused on a group of final year Engineering students' English Language writing anxiety (N=93) in relation to their gender, race and MUET results. The findings showed that the the male gender, Chinese and MUET band 4 participants faced higher levels of anxiety as compared to the other groups respectively. Somatic anxiety was recorded to be the highest subscale of anxiety faced by most of the participants. The findings of this study can help in making suitable amendments in the engineering programme course structure, especially in determining the suitable English papers to be offered to the students.
\end{abstract}

Keywords: English as a second language, language anxiety, second language writing anxiety, second language writing anxiety inventory, somatic anxiety, avoidance behaviour, cognitive anxiety

\section{Introduction}

Malaysia, aside from its official language, has made it a requirement that all Malaysians learn the English language in schools. However, Malaysians come from different racial backgrounds and none of these races have English as their mother tongue. Second Language Writing Anxiety (SLWA) is an aspect in second language learning that has been researched for many years and is considered one of the most crucial factors affecting all second language learning. As such, the issue of SLWA is worth being explored in depth.

According to Hassan (2001), SLWA can be defined as "a general avoidance of writing and of situations perceived by the individuals to potentially require some amount of writing accompanied by the potential for evaluation of that writing".

There has been a good amount of research which considers the relevance of writing anxiety in language learners from the foreign language perspective. Negari and Rezaabadi (2012) investigated the relationship between the students' anxiety in essay writing and their writing performance in EFL context. The research integrated several instruments, including the Second Language Writing Anxiety Inventory (SLWAI) developed by Cheng (2004) and that will also be the instrument used for this research.

Cheng (2004) analysed factors associated with second language writing anxiety and employed exploratory factor analysis and determined the final make-up of the Second language Writing Anxiety Inventory (SLWAI). The SLWAI consists of three subscales that are Somatic Anxiety, Avoidance Behavior, and Cognitive Anxiety. Somatic Anxiety refers to one's perception of the physiological effects of the anxiety experience, as reflected in increase in arousal of unpleasant feelings, such as nervousness and tension (Cheng, 2004: 316). Avoidance Behaviour refers to the behavioural aspect in the avoidance of writing (Cheng, 2004: 316). Cognitive anxiety refers to the mental aspect of anxiety experience, including negative expectations, preoccupation with performance and concern about others' perception (Cheng, 2004: 316). In her study, she found that the relationship between language anxiety and written performance is mainly due to cognitive anxiety.

Past researches on English as a Second Language (ESL) writing have shown that ESL writing anxiety has a certain amount of effect on ESL writing performance (Horwitz, 2001; Hassan, 2001). The findings derived from Cheng's study is supported by the study on SLWA conducted by Zhang (2011). Using Cheng's SLWAI instrument, she conducted a study of SLWA on Chinese English major students and found out that cognitive anxiety is the most common type of ESL writing anxiety experienced by learners. Both studies by Cheng (2004) and Zhang (2011) have revealed that cognitive anxiety is the highest level of anxiety faced by non-technical programme based (English Language major) students. 
Research has also shown that learners do feel language anxiety during writing examinations due to the lack of writing skills (Zhang, 2011) and the lack of language proficiency (Daud et al., 2003). These past studies revealed that linguistic difficulties, insufficient witing practice, fear of tests, lack of topical knowledge and low self-confidence in writing performance are the contributive factors that cause SLWA among learners.

The findings of several studies showed that the writing anxiety levels of the male students were higher than that of female students (Pajares and Valiante, 1997) and Zorbaz (2010). Ranjit and Rajalingam (2012) found that the higher the writing anxiety level, the better the students' level of proficiency. Also, this finding was supported by Horwitz (1991) and Onwuegbuzie, Bailey \& Daley (2000) where the researchers found that, the more an individual becomes anxious in writing, the better their performance in writing.

This study aimed to determine the level of SLWA of final year Engineering students in UPM as measured by their scores on Somatic Anxiety, Avoidance Behaviour and Cognitive Anxiety. It will also investigate whether significant relationships exist between the SLWA subscales and the participants' gender, race and Malaysian University English Test (MUET) results.

\section{Research questions}

1. What are the levels of SLWA faced by final year Engineering students in UPM?

2. Is there a significant relationship between the three subscales of SLWAI and the students' gender, race and MUET results?

\section{Significance of study}

The study can be significant as the findings can help universities make suitable amendments towards their course syllabi for technical programme offered. Also, the findings of this study will be beneficial for future researchers embarking on research in the field of SLWA among undergraduates who are enrolled in technical programme.

\section{Methodology}

This study was conducted among UPM Engineering final year students with a sample of 93 participants randomly selected. The sample consist of $51.6 \%$ females and $48.4 \%$ males. $71 \%$ of the students from the sample are at the age of 23-24.

For this study, the Second Language Writing Anxiety Inventory (SLWAI) was used to measure the level of English Language writing anxiety among the participants. The SLWAI consist of 22 items which encompasses three subscales. The first is Somatic Anxiety with 7 items, Avoidance Behaviour with 7 items, and Cognitive Anxiety with 8 items. There are 7 items in the SLWAI that require reverse scoring.

To determine the internal reliability of SLWAI, Cronbach's coefficient was calculated with a reliability estimate of .91 for the administration of the scale as reported by Cheng (2004). In addition, the test-retest coefficients were .85 . The Cronbach's coefficient was also calculated for each of the three subscales with .87 and .88 for Somatic Anxiety, .85 and .88 for Avoidance Behavior, and .82 and .83 for Cognitive Anxiety. Test-retest coefficients for the three subscales were .82 for Somatic Anxiety, .83 for Avoidance Behavior, and .81 for Cognitive Anxiety.

Cheng (2004) tested for the factorial validity of SLWAI with two separate factor analyses conducted for the two administrations of the SLWAI. The analysis results revealed that the SLWAI does not confound writing anxiety with beliefs about one's writing ability, thereby providing favourable evidence of discriminant validity of the SLWAI (Cheng, 2004).

The demographic information about the students were gathered by using a demographic questionnaire. With the survey, information on the students' gender, race and MUET results were collected.

\section{Findings and discussion}

SPSS version 19 was used to analyse data collected. Descriptive statistics were used in accordance to the SLWA inventory. The students answered a 22 -item likert scale survey. The range of choices were strongly agree, agree, uncertain, disagree and strongly disagree. The ranges were intended to measure different dimensions of writing anxiety: somatic anxiety, avoidance of behaviour and cognitive anxiety.

The dimensions of writing anxiety as presented in table 1 shows that somatic anxiety is significantly high among the participants as compared to other dimensions. As compared to past findings by Cheng (2004) and Zhang (2011) where participants faced higher level of cognitive anxiety, this study showed that somatic anxiety is the dimension with the highest mean score. This suggests that there might be a difference in the writing anxiety faced by technical and nontechnical programme based students. Technical programme based students might not be able to handle physiological pressure (nervousness, tension) that well as compared to non-technical programme based students.

Table 1 . Writing anxiety dimensions

\begin{tabular}{lccc}
\hline \multicolumn{1}{c}{ Writing Anxiety } & & & \\
\multicolumn{1}{c}{ Dimension } & $\mathrm{N}$ & Mean & Std. Deviation \\
\hline Somatic Anxiety & 93 & 3.2304 & .78530 \\
Avoidance Behaviour & 93 & 3.0614 & .46501 \\
Cognitive Anxiety & 93 & 2.8777 & .43924 \\
\hline
\end{tabular}


To determine the level of writing anxiety faced by the participants in terms of gender, Table 2 and 3 shows the results of both male and female respondents in accordance to the three dimensions of SLWA. The male participants were recorded to face higher level of writing anxiety in all three dimensions as compared to females. The respondents also showed a significantly high level of somatic anxiety as compared to the other dimensions. As for the female participants, while having recorded a higher level of somatic anxiety among the three dimensions, all three dimensions have a fairly average result.

This finding is supported by past researchers such as Pajares and Valiante (1997) and Zorbaz (2010) whereby female students have lower writing anxiety as compared to male students. Female students have more positive attitudes towards writing (Graham et al., 2007) and they enjoy writing more (Clark and Dugdale, 2009). Male engineering students might face higher levels of writing anxiety as they do not find writing English as enjoyable as subjects like Mathematics or Physics.

Table 2. Writing anxiety dimensions with reference to male gender

\begin{tabular}{llcc}
\hline \multicolumn{1}{c}{ Writing Anxiety } & & & \\
\multicolumn{1}{c}{ Dimension } & $\mathrm{N}$ & Mean & Std. Deviation \\
\hline Somatic Anxiety & 45 & 3.4635 & .78196 \\
Avoidance Behaviour & 45 & 3.1302 & .50491 \\
Cognitive Anxiety & 45 & 2.9389 & .51582 \\
\hline
\end{tabular}

Table 3. Writing anxiety dimensions with reference to female gender

\begin{tabular}{lccc}
\hline \multicolumn{1}{c}{ Writing Anxiety } & & & \\
\multicolumn{1}{c}{ Dimension } & $\mathrm{N}$ & Mean & Std. Deviation \\
\hline Somatic Anxiety & 48 & 3.0119 & .73071 \\
Avoidance Behaviour & 48 & 2.9970 & .41934 \\
Cognitive Anxiety & 48 & 2.8203 & .34873 \\
\hline
\end{tabular}

The results pertaining to race were also examined with reference to writing anxiety dimensions as presented in tables 4 to 6. The Chinese respondents recorded to have higher level of anxiety in all three dimensions as compared to the other two races. Also, the Chinese participants showed a relatively high level of somatic anxiety. The West Malaysia Bumiputra participants recorded the lowest mean score in somatic anxiety while the East Malaysia Bumiputra respondents showed the lowest mean score of avoidance behaviour and cognitive anxiety.

Rahil, Noran \& Habsah (1994) have reported that Malays have higher levels of anxiety compared to Chinese. However, the findings in this research highlighted Chinese students as having the highest levels of anxiety compared to the other two studied ethnic groups. This can be viewed as the indication that anxiety pertaining to race can be explored further by future researchers.

Table 4. Writing anxiety dimensions with reference to East Malaysia Bumiputra

\begin{tabular}{llcc}
\hline \multicolumn{1}{c}{ Writing Anxiety } & & & \\
\multicolumn{1}{c}{ Dimension } & $\mathrm{N}$ & Mean & Std. Deviation \\
\hline Somatic Anxiety & 13 & 3.1209 & .84686 \\
Avoidance Behaviour & 13 & 2.6923 & .52114 \\
Cognitive Anxiety & 13 & 2.6154 & .34027 \\
\hline
\end{tabular}

Table 5. Writing Anxiety dimensions wit reference to Chinese

\begin{tabular}{lccc}
\hline \multicolumn{1}{c}{ Writing Anxiety } & & & \\
\multicolumn{1}{c}{ Dimension } & $\mathrm{N}$ & Mean & Std. Deviation \\
\hline Somatic Anxiety & 37 & 3.6255 & .79136 \\
Avoidance Behaviour & 37 & 3.3012 & .35917 \\
Cognitive Anxiety & 37 & 3.0507 & .42742 \\
\hline
\end{tabular}


Table 6. Writing Anxiety dimensions wit reference to West Malaysia Bumiputra

\begin{tabular}{lccc}
\hline \multicolumn{1}{c}{ Writing Anxiety } & & & \\
\multicolumn{1}{c}{ Dimension } & $\mathrm{N}$ & Mean & Std. Deviation \\
\hline Somatic Anxiety & 43 & 2.9236 & .60957 \\
Avoidance Behaviour & 43 & 2.9668 & .42839 \\
Cognitive Anxiety & 43 & 2.8081 & .42464 \\
\hline
\end{tabular}

In tables 7 to 9, the three dimensions of SLWA have been represented in relation to the MUET results of the Engineering students. Nearly half of the participants scored a Band 3 in their MUET, with a quarter scoring Band 2 and Band 4 respectively. The results revealed that respondents who scored Band 4 faced significantly higher levels of anxiety in all three dimensions as compared to both Band 2 and 3 students. On the other hand, participants who have scored Band 2 showed low levels of anxiety. Both Band 2 and 4 participants showed higher levels of somatic anxiety, however Band 4 participants showed a much higher level as compared to Band 2 participants. Band 3 respondents on the other hand showed a slightly higher level of avoidance behaviour as compared to somatic anxiety.

According to past researchers such as Horwitz (1991) and Onwuegbuzie, Bailey \& Daley (2000), it was found that the higher the writing anxiety level, the better the students proficiency. Students who have scored Band 4 are considered more proficient in the English Language, as such, the students might feel more pressure and tension when faced with writing tasks and examinations. The desire to do well contributes to their effort in doing their best, thus resulting in higher levels of writing anxiety.

Table 7. Writing anxiety dimensions with reference to MUET Band 2

\begin{tabular}{lccc}
\hline \multicolumn{1}{c}{ Writing Anxiety } & & & \\
\multicolumn{1}{c}{ Dimension } & $\mathrm{N}$ & Mean & Std. Deviation \\
\hline Somatic Anxiety & 23 & 2.9814 & .56540 \\
Avoidance Behaviour & 23 & 2.8012 & .53058 \\
Cognitive Anxiety & 23 & 2.7065 & .51760 \\
\hline
\end{tabular}

Table 8. Writing anxiety dimensions with reference to MUET Band 3

\begin{tabular}{lccc}
\hline \multicolumn{1}{c}{ Writing Anxiety } & & & \\
\multicolumn{1}{c}{ Dimension } & $\mathrm{N}$ & Mean & Std. Deviation \\
\hline Somatic Anxiety & 41 & 3.0139 & .64824 \\
Avoidance Behaviour & 41 & 3.0453 & .38124 \\
Cognitive Anxiety & 41 & 2.8720 & .30681 \\
\hline
\end{tabular}

Table 9. Writing anxiety dimensions with reference to MUET Band 4

\begin{tabular}{lccc}
\hline \multicolumn{1}{c}{ Writing Anxiety } & & & \\
\multicolumn{1}{c}{ Dimension } & $\mathrm{N}$ & Mean & Std. Deviation \\
\hline Somatic Anxiety & 26 & 3.7308 & .91547 \\
Avoidance Behaviour & 26 & 3.2802 & .43609 \\
Cognitive Anxiety & 26 & 3.0288 & .51637 \\
\hline
\end{tabular}

\section{Conclusion}

Second language writing anxiety (SLWAI) among language learners has been a concern to many language educators. There were more studies carried out in the area of SLWA that focused on the non-technical field as compared to the technical field. As such, this present study attempts to highlight the level of anxiety faced by technical programme (engineering) students. Three types or dimensions of anxiety - somatic anxiety, avoidance behaviour and cognitive anxiety - have been explored. Based on the data presented in this paper, somatic anxiety marked the highest anxiety faced by most of the engineering students. The male respondents recorded the highest level of anxiety in all three dimensions compared to their female counterparts. This study also investigated the relationship between students' ethnicity and anxiety where the Chinese participants marked the highest anxiety level in all three dimensions compared to the other two races. Finally, the MUET results of the students have also indicated that the higher achievers of MUET; Band 4, faced more anxiety compared to the lower band achievers. The findings of this study can help programme designers/coordinators in respective engineering programmes to make suitable amendments in the engineering 
programme course structure, especially in determining the suitable English papers to be offered to their students. Thus, this findings provide pathway for future researchers who wish to explore the area of SLWA in a technical stream.

\section{References}

Cheng, Y. S. (2004). Scale development and preliminary validation. A measure of second language writing anxiety, 13, 313-335

Clark C, Dugdale G (2009). Young people's writing: Attitudes, behaviour and the role of technology. London: National Literacy Trust.

Daud, N. S. M., Daud, N. M., \& Kassim, N. L. A. (2003). Second language writing anxiety: Cause or effect?

Graham S, Berninger V, Fan W (2007). The structural relationship between writing attitudeand writing achievement in first and third grade students. Contemp. Educ., Psychol., 32(5): 16-536.

Hassan, B. A. (2001). The relationship of writing apprehension and self-esteem to the writing quality and quantity of EFI, Inniversitv students. Mansoura Facults of Fducation Journal, [Online] Available at : http://eric.ed.gov/PDFS/ED459671.pdf [Accessed: March.20, 2011].

Horwitz, E. K., Horwitz, M. B., \& Cope, J. (1986). Foreign language classroom anxiety. The Modern Language Journal, 70(2), 125-132.

Negari, G. M. \& Rezaabadi O. T. (2012). Too Nervous to Write? The Relationship between Anxiety and EFL Writing. Theory and Practice in Language Studies, 13(2), 2578-2586

Pajares F, Valiante G (1997). The predictive and mediational role of the writing self-efficacy beliefs of upper elementary students. J. Educ. Res., 90: 353-360.

Rahil Mahyuddin, Noran Fauziah Yaakub \& Habibah Elias (1994). Anxiety Towards Learning of English among Universiti Pertanian Malaysia Students. Akademika 45, 57-67.

Ranjit, T. K., \& Rajalingam, S. K. (2012) The Relationship of Writing Apprehension Level and Self-efficacy Beliefs on Writing Proficiency Level among Pre-university Students. English Language Teaching, 7(5), 42-52.

Zhang, H. X. (2011). A study on ESL writing anxiety among Chinese English majors - Causes, effects and coping strategies for ESL writing anxiety.

Zorbaz KZ (2010). "Elementary School Students' Writing Written Communication skills Relationship Between Anxiety and stiffness." Unpublished PhD Thesis, Institute of Educational Sciences, Gazi University, Ankara, Turkey. 